\title{
Closed-Form Duration Measures and Strategy Applications
}

\author{
Nelson J. Lacey \\ Sanjay K. Nawalkha
}

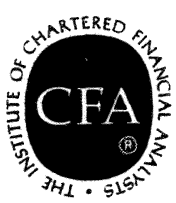

The Research Foundation of

The Institute of Chartered Financial Analysts 


\section{The Research Foundation of The Institute of Chartered Financial Analysts}

\section{Board of Trustees}

\author{
Chairman \\ James R. Vertin, CFA \\ Alpine Counselors \\ Vice Chairman \\ George W. Noyes, CFA \\ Standish, Ayer \& Wood, Inc.

\section{President} \\ Alfred C. Morley, CFA \\ Association for Investment \\ Management and Research \\ Darwin M. Bayston, CFA \\ Association for Investment \\ Management and Research \\ Thomas A. Bowman, CFA \\ Association for Investment \\ Management and Research
}

\section{Review Board}

\section{Research Director}

Charles A. D'Ambrosio, CFA

University of Washington

Gerald 0. Bierwag

University of Arizona

Joanne M. Hill

PaineWebber, Inc.

Alfred C. Morley, CFA

President

Darwin M. Bayston, CFA

Executive Vice President

Gary P. Brinson, CFA

Brinson Partners, Inc

Charles D. Ellis, CFA

Greenwich Associates

Frederick L. Muller, CFA

Atlanta Capital Management

William F. Sharpe

Sharpe-Tint, Inc.

Eugene C. Sit, CFA

Sit Investment Associates, Inc.

Walter P. Stern, CFA

Capital Research Co.

Donald L. Tuttle, CFA

Indiana University

Mark P. Kritzman, CFA

Windham Capital Management

Richard Roll

UCLA

Roll \& Ross Asset Management

Gary G. Schlarbaum, CFA

Miller, Anderson \& Sherrerd

\section{Officers}

Thomas A Bowman, CFA

Senior Vice President

Katrina F. Sherrerd

Vice President 


\section{Mission}

The mission of the Research Foundation is to identify, fund, and publish research material that:

- expands the body of relevant and useful knowledge available to practitioners;

- assists practitioners in understanding and applying this knowledge; and

- enhances the investment management community's effectiveness in serving clients.

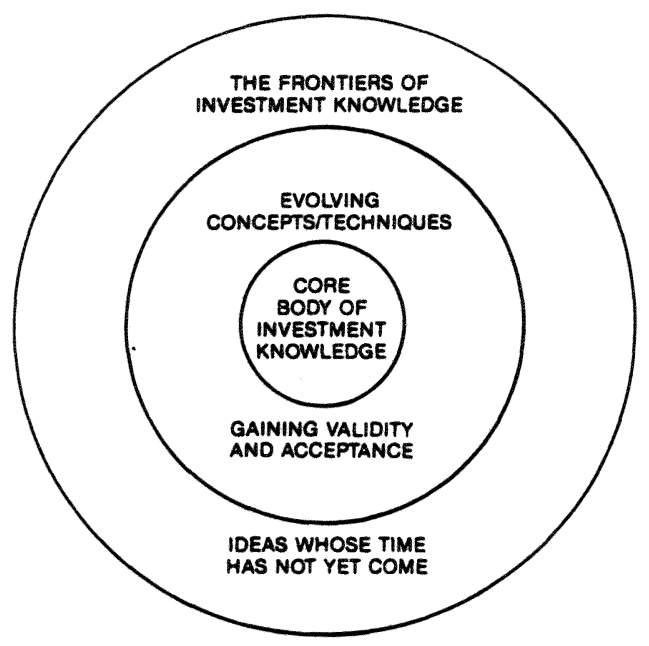

The Research Foundation of

The Institute of Chartered Financial Analysts

P.O. Box 3668

Charlottesville, Virginia 22903

(804) $977-6600$ 
(C) 1990 The Research Foundation of the Institute of Chartered Financial Analysts.

All rights reserved. No part of this publication may be reproduced, stored in a retrieval system, or transmitted, in any form or by any means, electronic, mechanical, photocopying, recording, or otherwise, without the prior written permission of the copyright holder.

This publication is designed to provide accurate and authoritative information in regard to the subject matter covered. It is sold with the understanding that the publisher is not engaged in rendering legal, accounting, or other professional service. If legal advice other expert assistance is required, the services of a competent professional should be sought.

From a Declaration of Principles jointly adopted by a Committee of the American Bar Association and a Committee of Publishers.

ISBN 10-digit: 0-943205-05-0 ISBN 13-digit: 978-0-943205-05-2

Printed in the United States of America.

Joni L. Tomal, Editor

Susan S. Brennan, Production Editor

Nina D. Hutchinson, Typography/Layout 


\title{
Closed-Form Duration Measures and Strategy Applications
}

\author{
by \\ Nelson J. Lacey \\ University of Massachusetts \\ and \\ Sanjay K. Nawalkha \\ University of Massachusetts
}

The Research Foundation of

The Institute of Chartered Financial Analysts 


\section{Table of Contents}

Acknowledgements $\ldots \ldots \ldots \ldots \ldots \ldots \ldots \ldots \ldots$ ix

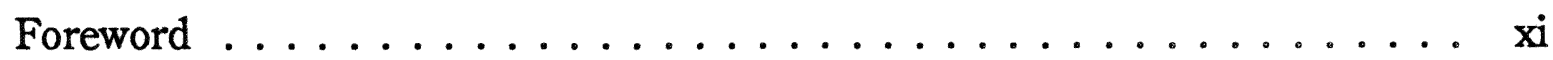

Introduction $\ldots \ldots \ldots \ldots \ldots \ldots \ldots \ldots \ldots \ldots \ldots \ldots \ldots \ldots$ xiii

Chapter 1. Closed-Form Formulas for Macaulay Duration $\ldots \ldots \ldots 1$

Chapter 2. Closed-Form Formulas for More Complex

Duration Measures . . . . . . . . . . . . . . . . . 9

Chapter 3. Convexity as a Measure of Interest-Rate Risk f . . . . . . . . 13

Chapter 4. Application of More Complex Duration Measures to Portfolio Immunization . . . . . . . . . . . . . . . . 17

Appendix A . . . . . . . . . . . . . . . 23

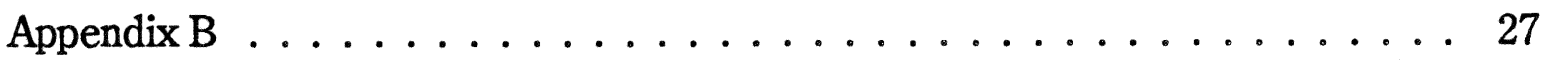

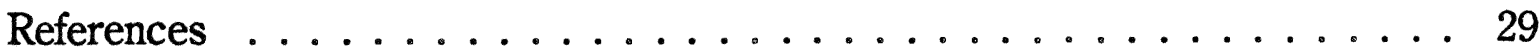




\section{Acknowledgements}

We are indebted to some key individuals who have helped us along the way. First, to the Research Foundation for supporting this research. Next to Donald R. Chambers, whose ideas have provided a base from which much of the monograph has developed. Finally, to Charles A. D'Ambrosio, who provided both the opportunity and the encouragement to develop this monograph.

Nelson J. Lacey Sanjay K. Nawalkha 


\section{Foreword}

Is there a relatively simple way to view duration and immunization when nonparallel shifts occur in the term structure of interest rates? What happens to duration calculations when the shift in interest rates is large? Is convexity all that it is implied to be? These are some of the questions addressed in this study. Closed-form duration measures are the vehicle for finding the answers.

Lacey and Nawalkha present us with the major closed-form duration formulas and several significant applications for bond analysts. The intuition and techniques for calculating duration are presented concisely and systematically.

Recall that duration measures an asset's price sensitivity to interest-rate changes. Remember also that duration calculations require the solution to a sum of a long series of present values of weighted, multiperiod cash flows. Closed-form formulas not only calculate duration but also eliminate the need for tedious summations.

You do not need to be mathematically sophisticated to use closed-form formulas. If you understand the basic intuition and own a calculator with a $y^{\mathbf{x}}$ function, you are able to solve even a seemingly overwhelming problem with comparative ease. Take equations 27 and 32 , for example. They may appear formidable, but they require only three and four inputs, respectively, to be solved. Fortunately, with closed-form duration formulas, most of the inputs-such as coupon rate, yield to maturity, and the number of periods to maturity-are readily available.

Lacey and Nawalkha's analysis is meaningful to all practitioners, even though it focuses primarily on bonds. Its most obvious import is on duration of pension assets and liabilities-the immunization process. Yet, bond duration also lays the foundation for estimates of equity duration, a concept that is becoming more and more prominent. The Research Foundation is pleased to present this practical analysis to its constituents.

Charles A. D'Ambrosio, CFA

The Research Foundation of the Institute of Chartered Financial Analysts 


\section{Introduction}

Bond-price volatility has increased dramatically over the past decade. Over the 1977-86 period, for example, the dispersion of bond returns, as measured by their standard deviation around long-term U.S. government bond returns, was twice that of any previous 10-year period and three to four times greater than in most other 10-year periods over the past 40 years. Recently, swings in the values of bond portfolios have been in ranges previously reserved for the Standard \& Poor's 500 Composite Index.

With greater volatility in bond markets, participants in those markets-especially pension funds, insurance companies, and depository institutions-have sought new ways to identify and manage interest-rate risk. Innovations include the use of derivative securities such as options and futures, bond swaps, and dedication. So far, bond-portfolio immunization has proved to be a most popular approach.

Immunization strategies are similar to those of portfolio insurance in that they are designed to protect a portfolio's nominal value from unexpected shifts in interest rates. They do so by guaranteeing some level of return over a specified time period. The popularity of immunization lies primarily in its flexibility; it imposes a limited set of restrictions on a portfolio's constituent securities and imposes few institutional constraints.

A bond's price sensitivity to interest-rate changes, measured by its "duration," is a key input to any immunization scheme. There are several ways to conceptualize duration. Most bond managers associate duration with Frederick Macaulay (1938), who was the first to define duration as a weighted average term to maturity of a bond's cash flows. Other people (Hicks 1939, Samuelson 1945, and Redington 1952) define duration in terms of the sensitivity of a bond's price to a change in interest rates, which is really a measure of elasticity. Redington demonstrated that a company, by choosing appropriate assets and liabilities, can immunize itself against the possibility of loss resulting from a change in interest rates.

There are two broad types of duration: scalar measures and vector measures. Scalar measures use one factor to capture changes in spot yields across the term structure. The simple Macaulay duration, for example, is a scalar measure. It provides a linear measure of bond-price sensitivity to a spot-rate change: If the spot rate changes by $x$ percent, the bond price may be expected to change by $y$ percent. But Macaulay duration does not take into account many of the real-world complexities of term-structure shifts. It does not, for example, provide a good description of bond-price sensitivity when, say, six-month rates change by $x$ percent but ten-year rates change by $z$ percent. Nor does it provide a good measure of sensitivity if bond-price responses vary with the size of the change in spot rates. In fact, Macaulay duration provides a good approximation of bond-price sensitivity to term-structure shifts only under the very limiting case in which interest rates shift by parallel, infinitesimal, and instantaneous amounts.

Not all scalar measures are so restricted. Fisher and Weil (1971), for example, developed a scalar measure that allows for parallel shifts in non-flat term structures. A scalar measure developed by Bierwag, Kaufman, and Toevs (1983) allows for unequal shifts between short- and long-term rates (but requires that the parameters defining the relative changes in yields be specified beforehand). All scalar measures, however, require that changes in spot yields across the term structure be perfectly correlated.

Empirical research to date indicates that the basic Macaulay duration works about as well as other scalar measures. Researchers have been quick to point out, however, that the restrictive assumptions underlying the scalar measures are surely violated in real-world portfolio settings. 
The viability of duration as a measure of bond-price sensitivity and bond-portfolio immunization as an implementation of duration has thus come into question.

At the same time, duration research has not stood still. To address the shortcomings of Macaulay and other scalar duration measures, researchers have developed a variety of vector, or multifactor, models. Vector measures (such as those developed in Cooper 1977 and later extended in Chambers, Carleton, and McEnally 1988) use more than one factor to capture changes in spot yields across the term structure, so they do not require that such changes be perfectly correlated.

Vector measures have the further advantage of not requiring the prespecification of relative changes in spot rates (a shortcoming of the scalar measure used by Bierwag, Kaufman and Toevs). Because relative changes in spot yields cannot in reality be prespecified, the vector approach may be expected to be more effective than earlier scalar duration models. In fact, empirical tests (Chambers, et al. 1988) demonstrate that they offer significant improvement over the performance of traditional scalar models and, more importantly, near-perfect immunization.

Vector models, by addressing the restrictions inherent in Macaulay and other simple duration measures, go some way toward answering the criticisms of duration and its implementation in bond immunization. They also pave the way for new and broader applications of duration research to bond-portfolio management. But vector models have their downside: Moving from scalar to vector models introduces new complexities to the process of interest-rate-risk control.

The main objective of this study is to introduce a range of duration measures and to demonstrate how these measures may be applied in the context of bond immunization. The duration measures given are in closed form. Closed-form solutions for duration provide the user with formulas that eliminate the need to sum present values of weighted multi-period cash flows. Closed-form equations thus alleviate much of the computational burden. The approach presented focuses on model implementation rather than model development. In other words, our goal is to further the reader's ability to utilize duration models.

The following chapters present a range of duration measures and discuss how these measures may be used in bond-portfolio management. Chapter 1 presents the many closed-form formulas for Macaulay duration. We show that these specifications are consistent with each other. Chapter 2 introduces more complex duration models. Chapter 3 presents one of the more popular complex measures-convexity-and discusses its advantages and disadvantages as a measure of interest-rate risk. Finally, Chapter 4 demonstrates the application of more complex duration measures in portfolio-immunization strategies and assesses their relative performance. 


\section{Closed-Form Formulas for Macaulay Duration}

This chapter is devoted exclusively to scalar measures of duration-in particular, the many closed-form solutions available for Macaulay duration. ${ }^{1}$ Closed-form solutions have the advantage of removing much of the computational burden associated with summing quantities over time or samples. This property is especially important with duration because of the number of cash-flow summations that are required. Although closed-form Macaulay duration formulas are similar, they differ with respect to the number of input variables required and the assumed cash-flow stream of the security. Thus, a particular formula may be more appropriate or less appropriate depending upon the characteristics of the bond(s) being analyzed and the inputs available. We first present nine closed-form solutions of Macaulay duration that are valid only at coupon payment dates. We next illustrate how these nine measures may be generalized to calculate duration at any time over a bond's life.

\section{The Case of Regular Bonds}

The formula for Macaulay's (1938) measure of duration is:

$$
D=\frac{i}{i-1}-\frac{Q i+N(1+Q-Q i)}{i^{N}-1-Q+Q i} \text {. }
$$

This specification requires three input variables:

$i=$ the bond's yield to maturity,

$Q$ - the ratio of the bond's coupon payment to the bond's face value, and

$\mathrm{N}=$ the bond's maturity.

Closed-form duration formulas did not gain widespread use until the 1980s, when Chua (1984) provided the following closed-form solution:

$$
D=\frac{C\left[\frac{(1+i)^{N+1}-(1+i)-i N}{i^{2}(1+i)^{N}}\right]+\frac{(F)(N)}{(1+i)^{N}}}{P} .
$$

Chua's derivation requires five input variables:

$\mathrm{N}=$ the number of periods to maturity,

$\mathrm{C}=$ the dollar coupon payment per period,

$i$ = the bond's yield to maturity,

$F=$ the bond's face value, and

$P=$ the bond's price.

${ }^{1}$ Duration, or the weighted average time to maturity of a bond, is given as:

$$
D=\frac{\sum_{t=1}^{N} \frac{t C}{(1+i)^{t}}+\frac{N F}{(1+i)^{N}}}{\sum_{t=1}^{N} \frac{C}{(1+i)^{t}}+\frac{F}{(1+i)^{N}}} .
$$


The price of the bond is determined as follows:

$$
P=\sum_{t=1}^{N} \frac{C}{(1+i)^{t}}+\frac{F}{(1+i)^{N}} .
$$

Equations (1) and (2) provide an exact numerical solution for Macaulay duration without requiring the summation of present values over the life of the bond.

Caks, Lane, Greenleaf, and Joules (1985) further simplified the calculation of duration by substituting the bond's price directly into equation (2):

$$
D=\frac{C(1+i)\left[(1+i)^{N}-1\right]+N i(F i-C)}{C i\left[(1+i)^{N}-1\right]+F^{2}} .
$$

Equation (3) requires only four input variables.

Nawalkha and Lacey (1988) further reduced the required set of input variables to three by replacing variables $\mathrm{C}$ and $\mathrm{F}$ in equation (2) with the bond's coupon rate (given by small c):

$$
D=\frac{c(1+i)\left[(1+i)^{N}-1\right]+(N i)(i-c)}{\operatorname{ci}\left[(1+i)^{N}-1\right]+i^{2}} .
$$

Babcock (1985) took a different approach to duration calculation, decomposing the bond's cash-flow stream into an annuity portion and a separate lump-sum portion:

$$
D=(y / i)\left[(1 / i)-\left\{1 /\left[i(1+i)^{N}\right]\right\}\right](1+i)+(1-y / i) N .
$$

The new input variable, $y$, is the bond's current yield (as opposed to its yield to maturity), defined as the bond's coupon payment as a percentage of its price. The solution for the present value of an annuity (PVIFA) is given by $\left[(1 / \mathrm{i})-\left\{1 /\left[i(1+i)^{\mathrm{N}}\right]\right\}\right]$.

Babcock's formula offers the following insights. For a par bond, whose yield to maturity equals its current yield (the term $y / i=1$ ), the formula reduces to (PVIFA) $(1+i)$. For a zero-coupon bond, the entire first term on the right-hand side of equation (5) drops out, and the second term reduces to the number of periods to maturity, $\mathrm{N}$.

A similar closed-form solution is given by Caks, et. al. (1985), who separate the bond's cash flow into a portion representing a zero-coupon bond and a portion representing a par bond:

$$
D=N-(y / i)\left(N-D_{p a r}\right),
$$

where $D_{\text {par }}$ is the duration of a par bond, defined above as $(\mathrm{PVIFA})(1+\mathrm{i})$. This formula provides additional insights. First, because bonds with higher coupons will have higher current yields (i.e., higher y's), bonds with relatively high coupons may be expected to have relatively lower durations than bonds with low coupons. Second, equation (6) illustrates the effect of bond premia and discounts on duration. All else equal, bond premia (defined as $y / i>1$ ) act to reduce duration, while bond discounts (defined as $y / i<1$ ) act to increase duration.

To summarize, at least six closed-form formulas for duration appear in the published literature. Although all produce the same numerical solution, these formulas differ with respect to the required input variables and the way in which the solution to duration is conceptualized. To illustrate, consider a 12-percent-coupon bond priced at par with three years to maturity. The bond's interest accrues every six months. The input variables for this bond are: 


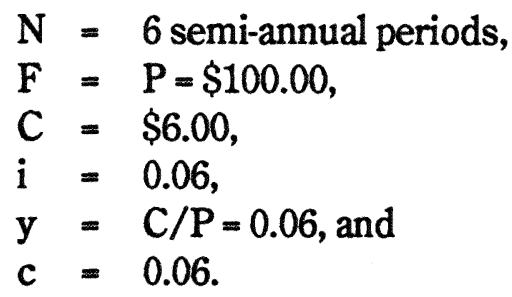

Given these inputs, the duration from equation (5), for example, would be:

$\mathrm{D}=(0.06 / 0.06)\left\{(1 / 0.06)-\left(1 /\left[0.06(1+0.06)^{6}\right]\right)\right\}(1+0.06)$

$=$ (1) $[16.667-(1 / 0.0851)](1.06)$

$=5.212$.

Table 1 lists the duration models given by equations (1) through (6), along with each model's required set of inputs. All the closed-form formulas produce an equivalent numerical solution for this bond's duration: 2.606 years, or 5.212 semi-annual periods.

\section{TABLE 1}

\section{A Comparison of Alternative Closed-Form Formulas for Macaulay Duration}

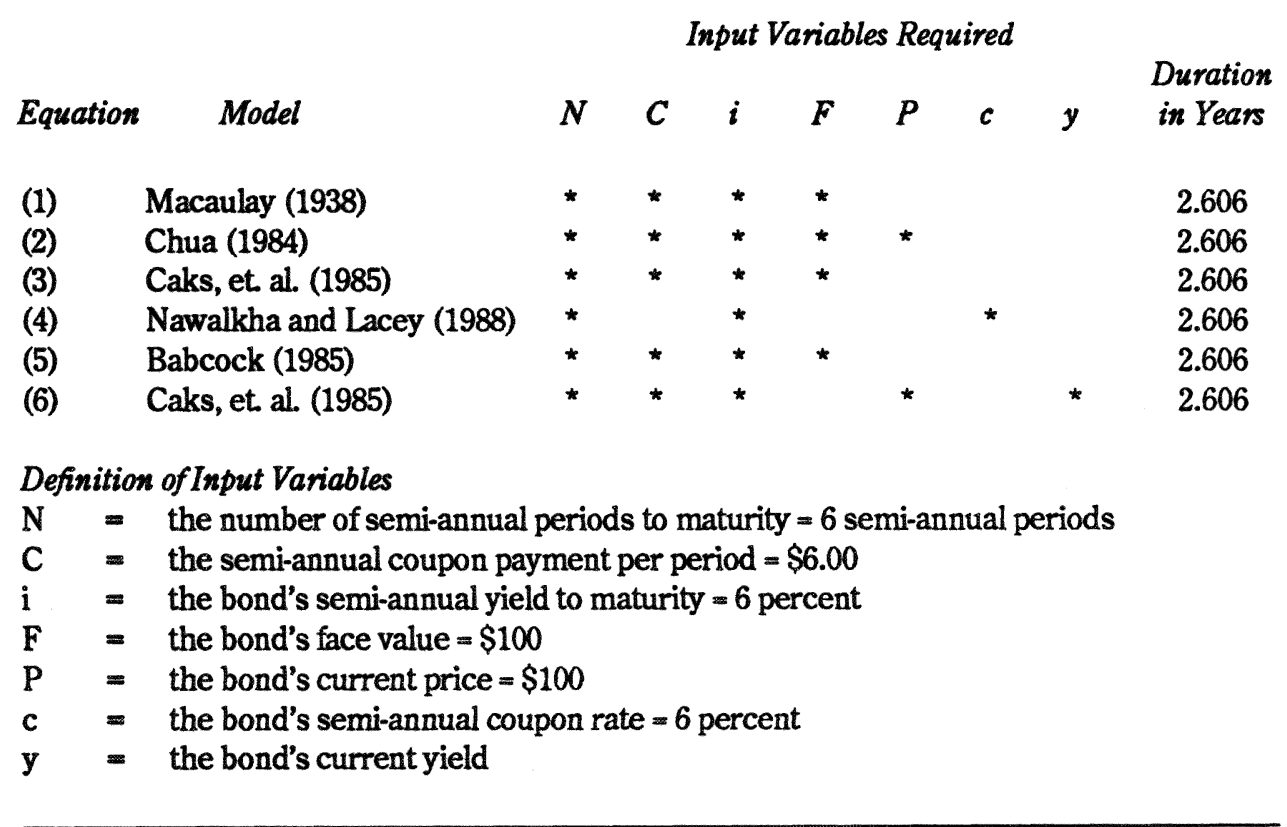

\section{Bonds With Special Cash-Flow Streams}

The closed-form formulas given above may be simplified further for bonds with special cash-flow streams, such as those of annuities, perpetuities, and zero-coupon bonds. As before, the objective is to provide an efficient method of calculation that reduces the computational burden. 
An annuity bond is a regular bond whose payment at maturity is amortized over the bond's life. The closed-form formula for annuities is obtained by substituting $\mathrm{F}=0$ in equation (3), which then simplifies to:

$$
D_{a n n}=\frac{(1+i)}{i}-\frac{N}{(1+i)^{N}-1},
$$

where $D_{\text {ann }}$ is the duration of an annuity of any length. Note that the duration of an annuity is independent of the size of the coupon and depends only on the time remaining to maturity, $\mathrm{N}$, and the yield to maturity, $i$.

A perpetuity is an annuity of infinite life. The closed-form formula for a perpetuity is derived from equation (7) by substituting $\mathrm{N}=\infty$ into the equation. This eliminates the entire second term. Denoting the duration of a perpetuity as $D_{\text {perp, we have: }}$

$$
D_{\text {perp }}=1+1 / i \text {. }
$$

The duration of the perpetuity depends only on its yield to maturity, $i$.

Zero-coupon bonds are bonds whose only cash flow is represented by the payment of the bond's face value at maturity. The duration of a zero-coupon bond is found by substituting $\mathrm{c}=0$ in equation (4):

$\mathrm{D}=\mathrm{N}$.

The duration of a zero-coupon bond is equal to its maturity.

Table 2 shows durations over different maturities and yields for annuities and perpetuities and compares these with the durations of bonds with regular cash-flow streams. We draw three conclusions from this table.

(1) If we hold time to maturity constant, while increasing yield to maturity, an annuity displays a more gradual decrease in duration than a bond with a regular cash-flow stream.

(2) If we hold yield to maturity constant, while increasing time to maturity, an annuity displays a more rapid increase in duration than a bond with a regular cash-flow stream.

(3) The duration of a perpetuity declines more rapidly with increasing yields than the duration of a bond with a regular cash-flow stream.

\section{Generalized Closed-Form Formulas for Macaulay Duration}

The formulas given thus far are valid only for bonds valued at coupon payment dates. The proper valuation of a bond between coupon payments will include interest accrued between the last coupon payment and the valuation date. Calculations of duration should take this accrued interest into account as well. In this section, we review closed-form duration solutions that are valid at any time over a bond's life.

Redefining $\mathrm{N}$ as the total number of coupons due until maturity (rather than the number of periods to maturity), the value of a bond between coupon payments is:

$$
P+f C=\sum_{t=1}^{N} \frac{C}{\left(1+i^{\prime}\right)^{t-f}}+\frac{F}{\left(1+i^{\prime}\right)^{N-f}},
$$




\section{TABLE 2}

\section{Calculating Duration for Annuities and Perpetuities}

\begin{tabular}{|c|c|c|c|}
\hline $\begin{array}{l}\text { Time to } \\
\text { Maturity }\end{array}$ & $\begin{array}{c}\text { Monthly Yield } \\
\text { to Maturity }\end{array}$ & $\begin{array}{c}\text { Duration } \\
\text { of the Annuity/ } \\
\text { Perpetuity }\end{array}$ & $\begin{array}{l}\text { Duration of } \\
\text { the Regular Bond } \\
\text { Counterpart }\end{array}$ \\
\hline \multicolumn{4}{|c|}{ Duration for Annuities [Equation (7)] } \\
\hline 360 Months & $0.08 / 12=0.006667$ & 114.76 Months & 136.28 Months \\
\hline 360 Months & $0.10 / 12=0.008333$ & 101.89 Months & 113.95 Months \\
\hline 360 Months & $0.12 / 12=0.010000$ & 90.70 Months & 97.22 Months \\
\hline \multicolumn{4}{|c|}{ Constant Yield to Maturity } \\
\hline 180 Months & $0.12 / 12=0.010000$ & 64.97 Months & 83.32 Months \\
\hline 240 Months & $0.12 / 12=0.010000$ & 76.74 Months & 90.82 Months \\
\hline 360 Months & $0.12 / 12=0.010000$ & 90.70 Months & 97.22 Months \\
\hline \multicolumn{4}{|c|}{ Duration for Perpetuities [Equation (8)] } \\
\hline & $0.08 / 12=0.006667$ & 150.99 Months & 136.28 Months \\
\hline & $0.10 / 12=0.008333$ & 121.00 Months & 113.95 Months \\
\hline & $0.12 / 12=0.010000$ & 101.00 Months & 97.22 Months \\
\hline
\end{tabular}

The counterpart bond is given as a bond that makes 360 monthly payments and returns its stated face value at the end of the 360 th month, or at maturity. The counterpart bond is assumed to be priced at par.

where

$N=$ the total number of coupons due until maturity,

$f=$ the time elapsed since the date of the last coupon payment divided by the time between two coupon payments,

$\mathrm{fC}=$ the dollar amount of interest that has accrued, and

$i^{\prime}=$ the bond's adjusted yield to maturity.

The adjusted yield includes accrued interest and is therefore different from the reported yield. All other variables have been defined previously.

The following closed-form Macaulay duration formula (Chua 1988) is valid at coupon payment dates as well as between those dates:

$$
D=\frac{C\left[\left(1+i^{\prime}\right)^{N}\left(1+i^{\prime}-i^{\prime}\right)-\left(1+i^{\prime}\right)-i^{\prime}(N-f)\right]+i^{2} F(N-f)}{i^{\prime 2}\left(1+i^{\prime}\right)^{N-f}(P+f C)} .
$$

This is a generalization of Chua's original formula, given in equation (2).

A simplification of the generalized Macaulay duration formula (Nawalkha and Lacey 1990) is obtained by removing input variables $\mathrm{P}, \mathrm{F}$, and $\mathrm{C}$, and introducing the coupon rate (small c):

$$
D=\frac{c\left[\left(1+i^{\prime}\right)^{N}\left(1+i^{\prime}-f^{\prime}\right)-\left(1+i^{\prime}\right)\right]+i^{\prime}(N-f)\left(i^{\prime}-c\right)}{c i^{\prime}\left[\left(1+i^{\prime}\right)^{N}-1\right]+i^{\prime 2}} .
$$

This derivation reduces the required set of input variables to four. 
Referring to the example used in Table 1-a bond with an annual coupon rate of 12 percent, priced at par, with six coupons remaining before maturity-assume the time elapsed since the last coupon payment is three months, so that $f=0.5$. The bond's reported yield to maturity is 6 percent, and its adjusted yield to maturity (from equation (10)) is 5.99 percent. The bond's duration, using either equation (11) or (12), is 2.356 years (4.712 semi-annual periods). This compares with a duration of 2.606 years (5.212 semi-annual periods) using the traditional formulas and serves to illustrate the effect of accrued interest in reducing duration.

Table 3 shows generalized duration solutions for different intervals between coupon payment dates and for changing yields to maturity. Through time, duration decays at a constant rate, $f$, defined in this example to be one month divided by six months, or 0.167 . Table 3 also shows that generalized duration is lower (higher) the higher (lower) the adjusted yield to maturity.

\section{TABLE 3}

\section{Calculating Duration Between Coupon Payment Dates}

\begin{tabular}{lllcll}
\hline & \multicolumn{4}{c}{ Months Until Next Coupon } \\
& 5 & 4 & 3 & 2 & 1 \\
\hline
\end{tabular}

Duration Decay Between Coupon Payments

$\begin{array}{lcccccc}\text { Generalized } & & & & & & \\ \text { Duration } & 5.213 & 5.046 & 4.879 & 4.712 & 4.545 & 4.378 \\ \text { Drift } & - & 0.167 & 0.167 & 0.167 & 0.167 & 0.167\end{array}$

Generalized Duration At Different Yields To Maturity *

Adjusted Yield

$\begin{array}{lllllll}\text { to Maturity } & 0.0650 & 0.0625 & 0.0600 & 0.0575 & 0.0550 & -\end{array}$

Generalized

$\begin{array}{llllll}\text { Duration } & 4.701 & 4.707 & 4.712 & 4.718 & 4.723\end{array}$

* Calculations are based on a par bond with an annual coupon of 12 percent and with six semi-annual coupon payments remaining before maturity. Durations are reported in semiannual time periods.

** Calculations are based on a par bond with an annual coupon of 12 percent, with six semi-annual coupon payments remaining before maturity, and with three months remaining until the next coupon payment. Both adjusted yields to maturity and durations are reported in semi-annual time periods. 
Although the generalized formulas of equations (11) and (12) give correct numerical solutions, there is a simpler way to incorporate accrued interest into the traditional duration measures. This simpler alternative involves a two-step process. First, compute duration using any of the traditional closed-form formulas, but use the number of coupons remaining to maturity in place of the number of periods to maturity, and use the adjusted yield to maturity (from equation (10)) in place of the reported yield to maturity ( $D^{\prime}$ represents the resulting adjusted duration measure). Second, subtract the amount of time elapsed since the last coupon payment divided by the time between two coupon payments, given by $\mathrm{f}$, from the adjusted duration measure to arrive at the generalized duration measure:

$$
D=D^{\prime}-f .
$$

This two-step method may be used to convert any traditional duration formula, such as given in equations (1) through (9), into a generalized formula that is valid both at and between coupon payment dates. 



\section{Closed-Form Formulas for More Complex Duration Measures}

The previous chapter presented closed-form solutions for Macaulay duration. We noted that, as a measure of interest-rate risk, Macaulay duration is applicable only when the term structure shifts by parallel, infinitesimal, and instantaneous amounts. When these assumptions are violated-which is likely in most portfolio settings-Macaulay duration is no longer a valid measure of interest-rate risk and may have little practical importance. Other duration measures attempt to deal with these restrictive assumptions. These new measures have the advantage of allowing for more realistic term-structure behavior, but they require a greater degree of sophistication on the part of the portfolio manager.

This chapter presents closed-form solutions for higher-order duration measures. Higherorder duration measures improve immunization performance by including slope, curvature, and other higher-order shifts in the term structure. For example, the first-order duration measure (simple Macaulay duration) captures only shifts in the height of the term structure, whereas second- and third-order measures capture slope and curvature shifts as well. These measures are obtained by raising the weighted average of the term to maturity to higher powers; thus, the second-order duration measure is the weighted average term to maturity squared, the third-order duration measure is the weighted average term to maturity cubed, and so on.

Our objective in this chapter is to show how these measures are computed and to introduce an algorithm that can be easily programmed on a spreadsheet. Providing the computational technique for more sophisticated duration measures may not help the reader understand why these measures are useful. Suffice it to say that these duration measures are designed to immunize bond portfolios for virtually any term-structure shift, and thus represent a significant departure from Macaulay's measure. Once the reader becomes familiar with the mechanics of computing these measures, specific applications should be easier to assimilate. Some specific applications are presented in Chapters 3 and 4.

\section{Duration Measures at Coupon Payment Dates}

To obtain duration measures that are valid at coupon payment dates, we follow the method of Nawalkha and Lacey (1988). The basic formula is:

$$
D(m)=\frac{\sum_{t=1}^{N} \frac{t^{m} C}{(1+i)^{t}}+\frac{N^{m} F}{(1+i)^{N}}}{\sum_{t=1}^{N} \frac{C}{(1+i)^{t}}+\frac{F}{(1+i)^{N}}},
$$

where

$C=$ the bond's coupon per period,

$i$ = the bond's yield to maturity,

$\mathrm{N}=$ the number of periods to maturity,

$\mathrm{m}=$ the order of the formula ( $\mathrm{m}$ may be any positive integer), and

$\mathrm{F}=$ the bond's face value. 
When $m=1$, equation (14) is equivalent to the Macaulay duration measures given in Chapter 1 .

Substituting $\mathrm{F}=\mathrm{C} / \mathrm{c}$ into equation (14), where $\mathrm{c}$ is the coupon rate per period, equation (14) may be rewritten as:

$$
D(m)=\frac{i\left[c S_{m}(1+i)^{N}+N^{m}\right]}{c\left[(1+i)^{N}-1\right]+i},
$$

where $S_{m}$ equals the summation term:

$$
\mathrm{S}_{\mathrm{m}}=\sum_{\mathrm{t}=1}^{\mathrm{N}} \frac{\mathrm{t}^{\mathrm{m}}}{(1+\mathrm{i})^{\mathrm{t}}}
$$

A closed-form solution for $S_{m}$ would allow us to derive a closed-form solution for $D(m)$. The closed-form solution for $S_{m}$ (derived in Appendix $A$ ) is given by:

$$
S_{m}=\frac{1}{i}\left[1+\sum_{t=0}^{m-1} C_{t} S_{t}-\frac{(1+N)^{m}}{(1+i)^{N}}\right] \text { for all } m \geq 1 \text {, }
$$

where:

$$
\mathrm{m}_{\mathrm{t}}=\frac{\mathrm{m} !}{(\mathrm{m}-\mathrm{t}) ! \mathrm{t} !} \text {, and } \mathrm{S}_{\mathrm{m}}=\frac{1}{\mathrm{i}}\left[1-\frac{1}{(1+\mathrm{i})^{\mathrm{N}}}\right] \text { for } \mathrm{m}=0 \text {. }
$$

Equations (16) and (17) may be used to specify any value of $\mathrm{S}_{\mathrm{m}}$. As equation (17) suggests, $\mathrm{S}_{0}$ is specified as follows:

$$
\mathrm{S}_{0}=\frac{1}{\mathrm{i}}\left[1-\frac{1}{(1+\mathrm{i})^{\mathrm{N}}}\right]
$$

Higher-order values for $S_{m}$ may be obtained by building on preceding lower-order values. Thus, for $\mathrm{S}_{1}, \mathrm{~S}_{2}$, and $\mathrm{S}_{3}$ :

$$
\begin{aligned}
& S_{1}=\frac{1}{i}\left[1+S_{0}-\frac{(1+N)}{(1+i)^{N}}\right] \\
& S_{2}=\frac{1}{i}\left[1+S_{0}+2 S_{1}-\frac{(1+N)^{2}}{(1+i)^{N}}\right], \text { and } \\
& S_{3}=\frac{1}{i}\left[1+S_{0}+3 S_{1}+3 S_{2}-\frac{(1+N)^{3}}{(1+i)^{N}}\right] .
\end{aligned}
$$

Substituting the value of $S_{0}$ from equation (18) into equation (19) and simplifying, we arrive at the following workable formula for $\mathrm{S}_{1}$ :

$$
S_{1}=\frac{(1+i)\left[(1+i)^{N}-1\right]-(N i)}{i^{2}(1+i)^{N}}
$$


Similar substitutions yield workable formulas for $\mathrm{S}_{2}$ and $\mathrm{S}_{3}$ :

$$
\begin{aligned}
& S_{2}=\frac{(1+i)(2+i)\left[(1+i)^{N}-1\right]-(N i)[N i+2(1+i)]}{i^{3}(1+i)^{N}}, \text { and } \\
& S_{3}=\frac{(1+i)\left[i^{2}+6(1+i)\right]\left[(1+i)^{N}-1\right]-3 N i(1+i)(2+i)-i^{2} N^{2}[3(1+i)+N i]}{i^{4}(1+i)^{N}} .
\end{aligned}
$$

Note that, although these equations look formidable, they involve only simple math and two variables, $\mathrm{i}$ and $\mathrm{N}$.

A closed-form solution for $D(m)$ is now obtainable by substituting the solution(s) for $S_{m}$ into equation (15). Exhibit 1 presents a general schematic illustrating the procedure. It may be used to obtain duration measures of any order. An $\mathrm{m}^{\text {th }}$-order duration measure, for example, would be obtained as follows:

$$
S_{0}, S_{1}, \ldots, S_{m-1} E q .(16) \longrightarrow S_{m} \stackrel{E q .(15)}{\longrightarrow} D D(m) .
$$

\section{EXHIBIT 1}

\section{Schematic Illustrating the Algorithm for Higher-Order Duration Measures}

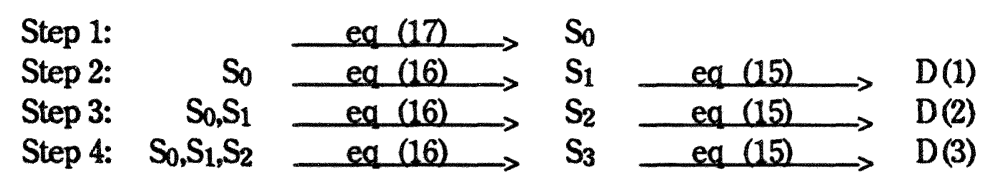

Based on this approach, closed-form formulas for the first-, second-, and third-order duration measures are:

$$
\begin{aligned}
& D(1)=\frac{c(1+i)\left[(1+i)^{N}-1\right]+(N i)(i-c)}{c i\left[(1+i)^{N}-1\right]+i^{2}}, \\
& D(2)=\frac{c\left[(1+i)(2+i)\left[(1+i)^{N}-1\right]-(2 N i)(1+i)\right]+N^{2} i^{2}(i-c)}{c^{2}\left[(1+i)^{N}-1\right]+i^{3}} \text {, and } \\
& D(3)=\frac{\left[c \left\{(1+i)\left[i^{2}+6(1+i)\right]\left[(1+i)^{N}-1\right]-3 N i(1+i)(2+i)\right.\right.}{\left.-\left(i^{2} N^{2}\right)[3(1+i)+N i]+\left(N^{3} i^{4}\right)\right]} \\
& c\left(i^{3}\right)\left[(1+i)^{N}-1\right]+i^{4}
\end{aligned}
$$

Using these equations requires only simple arithmetic and a small number of variables-in this case, coupon rate (c), yield to maturity (i), and number of periods to maturity $(\mathrm{N})$.

Duration measures of orders higher than three are cumbersome to calculate and report. The basic procedure, however, follows that for $D(1), D(2)$, and $D(3)$. It is possible to write computer programs to calculate these values. For example, using a spreadsheet program, previous values of $\mathrm{S}_{\mathrm{m}}$ (i.e., $\mathrm{S}_{0}, \mathrm{~S}_{1}, \ldots, \mathrm{S}_{\mathrm{m}-1}$ ) may be stored in cells and copied into equation (16) to give values of $S_{m}$, according to the method illustrated in Exhibit 1. The appropriate value of $S_{m}$ may then 
be copied into equation (15), also stored in a spreadsheet, to obtain $D(m)$. (Nawalkha and Lacey 1988 provide an example of this technique.)

To illustrate, consider an 8 percent coupon bond with five years to maturity priced to yield 5 percent. Through a series of substitutions from equations (15), (16), and (17), following the schematic given in Exhibit 1, Exhibit 2 gives solutions for the first three duration measures.

\section{EXHIBIT 2}

\section{Solutions for Higher-Order Duration Measures}

\begin{tabular}{|c|c|c|c|c|c|c|c|}
\hline tep & So & $=4.3$ fror & equat & n 17. & & & \\
\hline Step & & $\mathrm{eq}$ (16) & $\mathrm{S}_{1}=$ & 12.6 & eq (15) & $D(1)=$ & 4.4 \\
\hline Step 3 & $S_{0}, S_{1}$ & $\mathrm{eq}(16)$ & $S_{2}=$ & 45.1 & eq (15) & $D(2)=$ & 20. \\
\hline Step 4: & $\mathrm{S}_{0}, \mathrm{~S}_{1}, \mathrm{~S}_{2}$ & $\mathrm{eq}(16)$ & $S_{3}=$ & 182.1 & eq (15) & $D(3)=$ & 99.6 \\
\hline
\end{tabular}

\section{Generalized Higher-Order Duration Measures}

In this section, we present closed-form solutions for higher-order duration measures that are valid not only at coupon payment dates, but also between those dates. As noted in Chapter 1, proper bond valuation between coupon payments must include interest that has accrued between the last coupon payment and the valuation date. The solutions given in this section modify those given by equations (15) and (16) by including this accrued interest.

The value of a bond between coupon payments was given by equation (10) in Chapter 1. Remember that, for the generalized formulas, the variable $\mathrm{N}$ defines the number of coupons until maturity (instead of the number of periods to maturity), and the variable $i^{\prime}$ defines the adjusted yield to maturity (as given in equation (10)) instead of the reported yield to maturity.

Using equation (14) as the basis, Nawalkha and Lacey (1990) derive a generalized higherorder duration formula that incorporates interest accrued between payment dates. Following an approach similar to that shown in Exhibit 1, the generalized closed-form formulas for first- and second-order duration measures are:

$$
\begin{aligned}
& D(1)=\frac{c\left[\left(1+i^{\prime}\right)^{N}\left(1+i^{\prime}-f^{\prime}\right)-\left(1+i^{\prime}\right)\right]+i^{\prime}(N-f)\left(i^{\prime}-c\right)}{c^{\prime}\left[\left(1+i^{\prime}\right)^{N}-1\right]+i^{2}} \text {, and } \\
& c\left\{\left(1+i^{\prime}\right)^{N}\left[\left(1+i^{\prime}-f^{\prime}\right)^{2}+1+i^{\prime}\right]-\left(1+i^{\prime}\right)\left[2\left(1+N i^{\prime}-f^{\prime}\right)+i^{\prime}\right]\right\} \\
& D(2)=\frac{+\mathrm{i}^{2}(\mathrm{~N}-\mathrm{f})^{2}\left(\mathrm{i}^{\prime}-\mathrm{c}\right)}{\mathrm{ci}^{\mathrm{i}^{2}}\left[\left(1+\mathrm{i}^{\prime}\right)^{\mathrm{N}}-1\right]+\mathrm{i}^{3}} \text {. }
\end{aligned}
$$

Generalized duration measures of orders higher than two are cumbersome to report. Just as with the basic, non-generalized measure, it is possible to write computer programs to calculate these values. Nawalkha and Lacey (1990) provide an expanded example and show that differences between non-generalized and generalized solutions are non-trivial.

The higher-order duration measures presented in this chapter serve as the foundation for the development of more sophisticated interest-rate-risk protection techniques. This foundation enables one to present any technique as a combination of lower- and higher-order measures. The bond convexity model, for example, may be given in terms of first- and second-order duration measures, and the duration vector model may be given in terms of the first- through fourth-order duration measures. Chapters 3 and 4 present these techniques. 


\section{Convexity as a Measure of Interest-Rate Risk}

Application of higher-order duration measures begins with the convexity model. Convexity may be viewed as a measure of the difference between a bond's estimated price change, as given by a Macaulay duration, and the actual price change when there is a non-infinitesimal shift in the term structure. The convexity model thus addresses one of the three criticisms of Macaulay duration: its requirement that shifts in the term structure be infinitesimal.

This chapter presents closed-form solutions for bond convexity. Convexity generally provides better estimates of bond-price volatility than Macaulay duration. There are, however, some overlooked disadvantages of using a convexity model to immunize bonds and bond portfolios.

\section{Closed-Form Solutions for Convexity}

Nawalkha, Lacey, and Schneeweis (1990) show that convexity may be expressed in terms of firstand second-order duration measures, as follows:

$$
\text { Convexity }=\frac{\partial^{2} \mathrm{P} / \partial \mathrm{i}^{2}}{\mathrm{P}}=\frac{\mathrm{D}(1)+\mathrm{D}(2)}{(1+\mathrm{i})^{2}} \text {. }
$$

where $i$ is the bond's yield to maturity. Closed-form solutions for $D(1)$ and $D(2)$ are given by equations (25) and (26) in Chapter 2. Substituting these solutions into equation (30) and simplifying them produces the closed-form solution for convexity:

$$
\text { Convexity }=\frac{2 c\left[(1+i)^{2}\left[(1+i)^{N}-1\right]-N i(1+i)\right]+\left[N(N+1)(i-c)\left(i^{2}\right)\right]}{[i(1+i)]^{2}\left[c\left([1+i]^{N}-1\right)+i\right]} .
$$

Equation (31) holds only at coupon payment dates, however. Computing convexity between coupon payment dates requires a generalized formula. The generalized formulas for (D1) and (D2) are given by equations (28) and (29) in Chapter 2. Substituting their solutions into equation (31) and simplifying, we arrive at the generalized closed-form solution for convexity:

$$
\text { Generalized Convexity }=\frac{\begin{array}{c}
c\left\{\left(1+i^{\prime}\right)^{N}\left[\left(1+i^{\prime}-f f^{\prime}\right)\left(1+2 i^{\prime}-f^{\prime}\right)+\left(1+i^{\prime}\right)\right]-\left(1+i^{\prime}\right)\right. \\
\left.\left[2\left(1+i^{\prime}+N i^{\prime}-f^{\prime}\right)\right]\right\}+i^{2}\left(i^{\prime}-c\right)(N-f)(1+N-f)
\end{array}}{\left.\left[i^{\prime}\left(1+i^{\prime}\right)\right]^{2}\left[c\left(1+i^{\prime}\right)^{N}-1\right\}+i^{\prime}\right]} .
$$

As with previous generalized formulas, $i^{\prime}$ represents adjusted (rather than reported) yield to maturity, and $\mathrm{N}$ represents the number of coupons (rather than periods) to maturity. Equation (32) is applicable both at and between coupon payment dates.

\section{Convexity as a Measure of Bond-Price Volatility}

Macaulay duration may be used to approximate the change in a bond's price caused by an instantaneous, infinitesimal, and parallel shift in the term structure. In Figure 1, the straight line with circles represents the Macaulay duration. The curved line represents the actual change in 


\section{FIGURE 1}

\section{Duration and Bond-Price Changes}

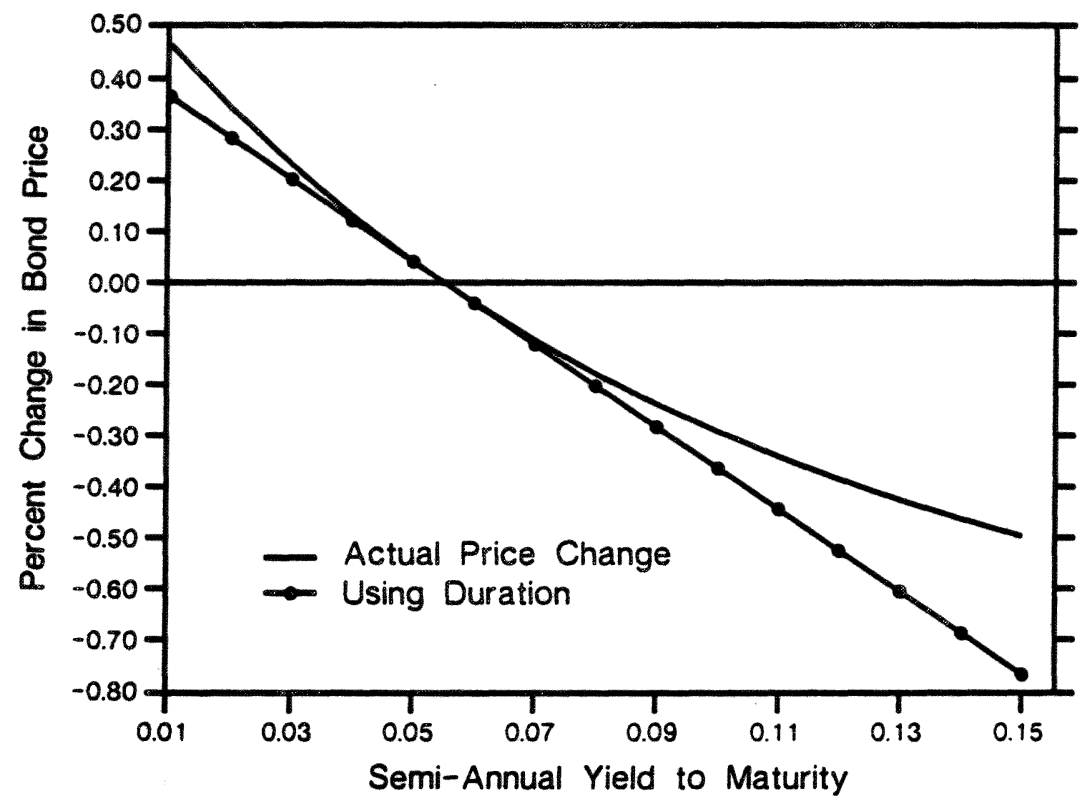

Source: Nawalkha, Lacey, and Chambers (1990).

bond prices caused by a change in yields. Note that the Macaulay duration approximates well the price change for small changes in yields, but poorly for large changes in yields. ${ }^{2}$

Adding convexity to the straight-line approximation given by Macaulay duration yields a superior approximation of overall price change. ${ }^{3}$ Figure 2 graphs the convexity curve against the actual changes in bond price. The convexity curve approximates the actual change in bond prices better than the linear Macaulay estimation, especially when yield shifts are large.

\section{The Desirability of High Convexity}

As demonstrated in Figure 2, convexity provides a better measure of bond-price volatility than the Macaulay duration when the term structure shifts by large amounts. Is convexity, therefore, a desirable characteristic in bonds? Given two bonds that have different convexities but are equal in every other way, should the portfolio manager always seek to hold the higher-convexity bond?

${ }^{2}$ With the Macaulay duration, the change in bond price is given as: $\mathrm{dP} / \mathrm{P}=-[\mathrm{D}(1) /(1+\mathrm{i})] \times \Delta \mathrm{i}$, where $\Delta \mathrm{i}$ is an infinitesimal shift in the term structure.

${ }^{3} \mathrm{~A}$ convexity term is added to the equation given in footnote 1 . The convexity term is given in the second term on the right-hand side of the equation below:

$$
\mathrm{dp} / \mathrm{P}=-[\mathrm{D}(1) /(1+\mathrm{i})] \times \Delta \mathrm{i}+1 / 2 \times \mathrm{C}[\Delta \mathrm{i}]^{2} \text {, }
$$

where $C$, convexity, is given by equation (35) or (36) in the text. 


\section{FIGURE 2}

\section{Convexity and Bond-Price Changes}

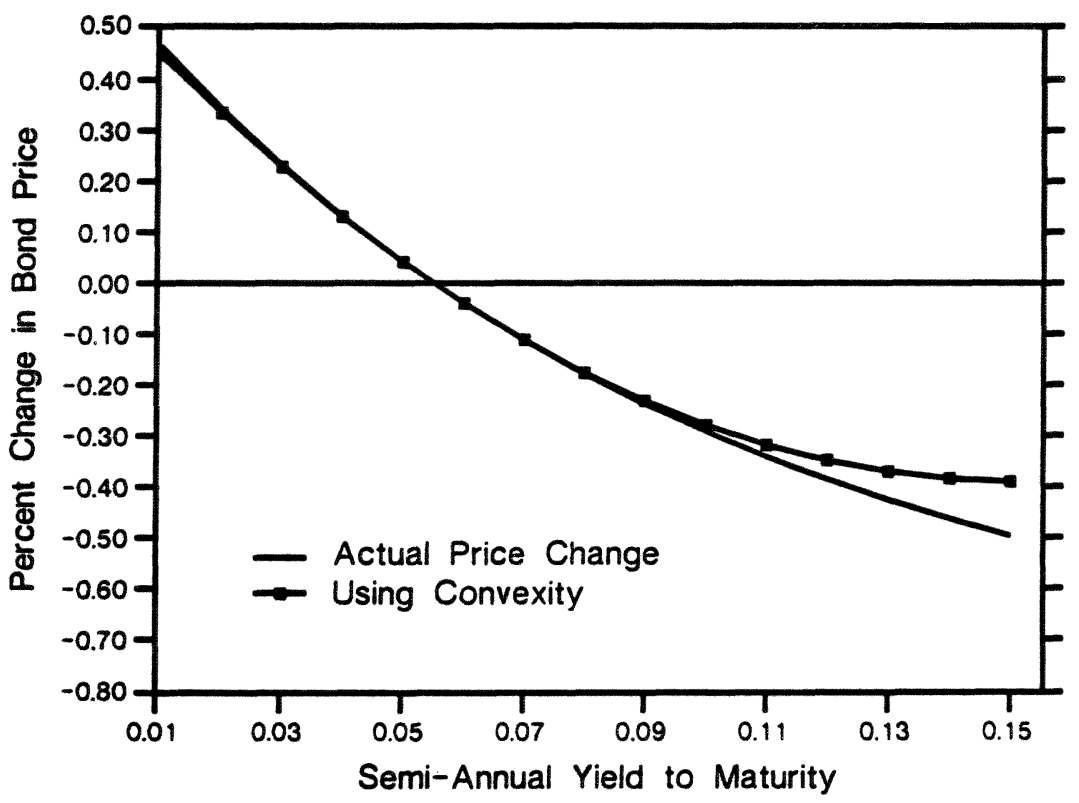

Source: Nawalkha, Lacey, and Chambers (1990).

Given the evidence in Figure 2, it would appear that higher convexity is always desirable. A higher-convexity bond will produce greater gains than a lower-convexity bond, whether interest rates shift up or down. Indeed, many researchers have argued that, because convexity is desirable, it is reflected in bond price. There are, however, important negative aspects of convexity (Nawalkha, Lacey, and Chambers 1990). Convexity, as noted, relaxes the assumption of non-infinitesimal shifts in the term structure, but it does not address other restrictive assumptions about the term structure. In particular, convexity does not address the assumption of parallel shifts in term structure.

When the term structure shifts by parallel amounts, higher-convexity bonds always produce slightly greater returns than lower-convexity bonds (Nawalkha, Lacey, and Chambers 1990; Hegde and Nunn 1988). When shifts are not parallel, however, the performance advantage of high-convexity bonds may disappear (Nawalka, Lacey, and Chambers 1990). They produce significantly lower returns than low-convexity bonds when short-term rates fall more or rise less than long-term rates, but retain a significant advantage when short-term rates fall less or rise more than long-term rates. Thus, convexity's desirability depends on the expected shift in the term structure.

The desirability of convexity in bond porffolios also depends on the expected shift in term structure (Lacey and Nawalkha 1990). High-convexity portfolios always outperform low-convexity portfolios when shifts are parallel. For non-parallel shifts, however, maximizing convexity produces higher gains in some cases but higher losses in others, whereas minimizing convexity results in lower losses and lower gains no matter what the shift. Given that most term structures 
do not exhibit parallel displacement, an investor implementing a risk-reduction strategy should always prefer to minimize convexity. ${ }^{4}$

Compared with Macaulay duration, convexity is a superior measure of bond-price volatility, given non-infinitesimal shifts in term structure. But convexity's desirability is ambiguous. When shifts in the term structure are not parallel, higher-convexity bonds outperform lower-convexity bonds in some cases but not in others. Minimizing the convexity of bond portfolios, however, results in lower losses (and also lower gains) no matter how the term structure shifts.

\footnotetext{
${ }^{4}$ This point is also made by Maloney and Loque (1989), who, in addition, reveal some negative aspects of convexity related to increased transaction costs.
} 


\section{Application of More Complex Duration Measures to Portfolio Immunization}

Immunization strategies are designed to guarantee some level of return over a specified planning horizon. Duration measures are key inputs to these strategies. The measure used may be the simple Macaulay duration or one of the many complex duration measures.

An obvious question is, which duration model works best? The simple Macaulay model, which assumes highly restrictive term-structure behavior, may be expected to perform well over relatively stable periods of interest-rate shifts but relatively poorly over more volatile periods. The portfolio manager must therefore keep an eye on interest-rate forecasts when choosing a duration model.

This concluding chapter presents three bond-portfolio immunization models based on the duration measures defined in Chapter 2. It also includes the results of a performance study that demonstrates the trade-offs involved in choosing among these three models.

\section{The Macaulay Duration Model}

The $\mathrm{D}(1)$ model, considered the simplest immunization model, assumes infinitesimal, instantaneous, and parallel shifts in term structure. Under these assumptions, the objective function and constraints of the $\mathrm{D}(1)$ model are:

$$
\begin{aligned}
& \text { Objective function: } \operatorname{Min} \sum_{i=1}^{n} p_{i}{ }^{2}, \\
& \text { Subject to: } \sum_{i=1}^{n} p_{i} D_{i}(1)=H \text {, and } \sum_{i=1}^{n} p_{i}=1,
\end{aligned}
$$

where

$$
\begin{aligned}
& \mathrm{p}_{\mathrm{i}}=\text { the proportion of investment held in the } \mathrm{i}^{\text {th }} \text { bond, } \\
& \mathrm{D}_{\mathrm{i}}(1)=\text { the Macaulay duration of the } \mathrm{i}^{\text {th }} \text { bond, } \\
& \mathrm{H}=\text { the planning horizon of the portfolio, and } \\
& \mathrm{n}=\text { the number of bonds held in the portfolio. }
\end{aligned}
$$

The constraints are designed to set the weighted average duration of the $D(1)$ model portfolio equal to the portfolio's planning horizon. An infinite number of solutions (i.e., an infinite combination of bond-portfolio holdings) satisfy this objective. The optimal solution, given by the objective function, is the one that minimizes the sum of squared bond proportions held. This solution has the benefit of maximum diversification.

\section{The M-Square Model}

The M-square model (Fong and Vasicek 1983) allows for both non-infinitesimal and non-parallel shifts in the term structure of interest rates. It thus provides superior protection relative to Macaulay duration, given more realistic interest-rate shifts.

Whereas duration is a time-to-maturity measure, $\mathrm{M}$-square is a variance measure. Minimizing portfolio M-square serves to minimize the variance of the maturities of the cash flows around 
the planning horizon. Specifically, the M-square model favors bonds with cash flows near the planning horizon over bonds with cash flows far from the planning horizon.

The model's objective function and constraints are:

Objective function: $\operatorname{Min} \sum_{i=1}^{n} p_{i}$ M-Square

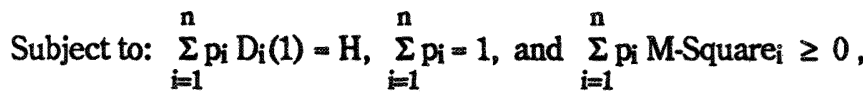

where $\mathrm{M}$-square $\mathrm{i}$ is the $\mathrm{M}$-square measure for the $\mathrm{i}^{\mathrm{th}}$ bond and is given as:

$$
\text { M-square }=\mathrm{D}(2)-2 \mathrm{HD}(1)+\mathrm{H}^{2} \text {. }
$$

Here $\mathrm{D}(2)$ is the generalized formula for second-order duration, given by equation (29) in Chapter 2.

Appendix B shows that the M-square model's objective function and constraints can be restated solely in terms of $D(1)$ and $D(2)$, as follows:

Objective function: $\operatorname{Min} \sum_{i=1}^{n} p_{i}^{2}$,

Subject to: $\sum_{i=1}^{n} p_{i} D_{i}(1)=H, \sum_{i=1}^{n} p_{i} D_{i}(2)=H^{2}$, and $\sum_{i=1}^{n} p_{i}=1$.

Whereas the objective function is equivalent to that of the Macaulay duration model and is subject to equivalent interpretation, the M-square model introduces a second duration constraint. This second constraint results in a zero M-square value for the portfolio. ${ }^{6}$

\section{The Duration Vector Model}

The duration vector, designed for virtually any interest-rate shift, is the most generalized model in terms of realistic term-structure behavior. The duration vector model is given by:

Objective function: $\operatorname{Min} \sum_{i=1}^{n} p_{i}^{2}$,

Subject to: $\sum_{j=1}^{n} p_{i} D_{i}(j)=(H)^{j},(j=1,2,3, \ldots, m)$, and $\sum_{i=1}^{n} p_{i}=1$

where $D_{i}(j)$ is the $j^{\text {th }}$-order duration measure for the $i^{\text {th }}$ bond. Although the model's objective function is equivalent to that of the Macaulay duration and M-square models, the duration vector model includes a vector of constraints (that is, $a j^{\text {th }}$-order constraint is defined for each value of

${ }^{5}$ The M-square model in this form demonstrates its equivalency to the two-factor duration model given by Bierwag, Kaufman, and Latta $(1987,1988)$, as well as to the model given by the first two elements of the Chambers, et al. (1988) duration vector model.

${ }^{6}$ This approach assumes that short positions can be allowed in the bond portfolio. The original derivation (Fong and Vasicek 1983) disallows short positions. 
$\mathrm{j}=1,2, \ldots, \mathrm{m})$. These higher-order duration constraints immunize the bond portfolio from slope, curvature, and other types of shifts in the term structure.

The similarities between the duration vector and the previous two models are apparent. The duration vector model requires an additional constraint for each additional element of the duration vector. The $\mathrm{D}(1)$ model may be considered a special case of the duration vector model when only the first element of the vector is used. Similarly, the M-square model may be considered the special case of the duration vector model when only the first two elements of the duration vector are used.

Increasing the number of elements considered by the duration vector has the advantage of improved immunization performance. The disadvantage, however, is that this results in a less-diversified portfolio (that is, a portfolio that requires larger long and short portfolio holdings).

\section{Performance Analysis and Comparison}

Chambers, et. al. (1988) report on the deviations between actual returns and target returns for each of the three models examined. They constructed 16 samples of Treasury-note portfolios, one for each quarter over the four-year period 1976-79. This period was characterized by high interest-rate volatility and large differences between the coupons on different bonds.

Chambers, et. al. estimated quarterly target returns using the zero-coupon yield from the underlying term structure over each quarter. Portfolios were liquidated at the end of each quarter, and actual returns were then compared with the target return for each model over each quarter examined. Table 4 reports these deviations. The relative magnitudes of the deviations indicate that the duration vector model outperformed the other models over most samples. (The M-square model was second best.) This might have been expected, because the more sophisticated models are designed to improve immunization performance for realistic term-structure shifts. The means of the absolute deviations, reported in Table 4, clearly show the superiority of the duration vector model.

As Table 5 shows, however, superior immunization performance comes at the cost of reduced portfolio flexibility. The sum of the squared portfolio weights is highest for the duration vector model and lowest for the Macaulay duration model. Larger portfolio weights imply larger long and short bond positions and larger transaction costs associated with portfolio rebalancing. The benefits of improved expected performance must be weighed against the disadvantages of reduced portfolio flexibility.

The immunization model of choice therefore becomes a matter of trading off the level of protection expected against the level of flexibility desired. The almost-perfect immunization of the duration vector model, however, suggests that more complex, higher-order duration measures have served to answer, at least partially, earlier criticisms of duration and its applications. Opportunities for innovation in this area remain. 


\section{TABLE 4}

\section{Single-Period Deviations of Actual Returns From Target Returns}

\begin{tabular}{|c|c|c|c|c|}
\hline $\begin{array}{l}\text { Sample } \\
\text { Number }\end{array}$ & $\begin{array}{l}\text { Target } \\
\text { Return }\end{array}$ & $\begin{array}{c}\text { Duration } \\
\text { Model } \\
D(1)\end{array}$ & $\begin{array}{c}\begin{array}{c}M \text { Square } \\
\text { Model }\end{array} \\
D(1), D(2)\end{array}$ & $\begin{array}{c}\begin{array}{c}\text { Duration } \\
\text { Vector Model }\end{array} \\
D(1) \text { to } D(4)\end{array}$ \\
\hline 1 & 1.01218 & 0.00261 & 0.00295 & 0.00053 \\
\hline 2 & 1.01196 & 0.00028 & -0.00043 & -0.00044 \\
\hline 3 & 1.01322 & -0.00470 & -0.00148 & 0.00057 \\
\hline 4 & 1.01524 & -0.00292 & -0.00075 & -0.00039 \\
\hline 5 & 1.01639 & 0.00141 & 0.00272 & 0.00010 \\
\hline 6 & 1.01693 & -0.00101 & -0.00049 & 0.00053 \\
\hline 7 & 1.01760 & -0.00015 & -0.00048 & 0.00072 \\
\hline 8 & 1.01917 & -0.01367 & -0.00770 & -0.00027 \\
\hline 9 & 1.02520 & 0.00122 & 0.00085 & 0.00045 \\
\hline 10 & 1.02510 & -0.00232 & -0.00069 & 0.00163 \\
\hline 11 & 1.02499 & 0.00021 & 0.00018 & -0.00135 \\
\hline 12 & 1.02520 & -0.00924 & -0.00272 & 0.00052 \\
\hline 13 & 1.03004 & -0.00116 & -0.00178 & 0.00383 \\
\hline 14 & 1.03152 & 0.02316 & 0.00995 & -0.00201 \\
\hline 15 & 1.02223 & -0.00036 & 0.00364 & 0.00174 \\
\hline \multicolumn{2}{|c|}{ Mean of Absolute Values } & 0.00429 & 0.00245 & 0.00101 \\
\hline \multicolumn{2}{|c|}{ Sum of Squared Deviations } & 0.00086 & 0.00020 & 0.00003 \\
\hline
\end{tabular}

* Although Chambers, et. al. report results using $D(1)$ through $D(7)$, we do not reprint those results because there was no significant gain in performance beyond $D(4)$.

Source: Chambers, Carleton, and McEnally (1988). 


\section{TABLE 5}

\section{Sum of Squared Portfolio Weights}

$\begin{array}{lccc}\text { Sample } & \begin{array}{c}\text { Duration } \\ \text { Model }\end{array} & \begin{array}{c}\text { M-Square } \\ \text { Model }\end{array} & \begin{array}{c}\text { Duration } \\ \text { Vector Model }\end{array} \\ & \begin{array}{c}\frac{\text { Mod }}{D(1), D(2)} \\ \text { D(1) to } D(4)\end{array} & & \\ 1 & 0.106 & 0.196 & 0.441 \\ 2 & 0.101 & 0.182 & 0.350 \\ 3 & 0.110 & 0.214 & 0.534 \\ 4 & 0.106 & 0.214 & 0.493 \\ 5 & 0.096 & 0.178 & 0.385 \\ 6 & 0.091 & 0.164 & 0.297 \\ 7 & 0.098 & 0.182 & 0.347 \\ 8 & 0.098 & 0.203 & 0.507 \\ 9 & 0.090 & 0.186 & 0.459 \\ 10 & 0.087 & 0.171 & 0.373 \\ 11 & 0.081 & 0.152 & 0.260 \\ 12 & 0.084 & 0.161 & 0.256 \\ 13 & 0.095 & 0.227 & 0.509 \\ 14 & 0.094 & 0.211 & 0.511 \\ 15 & 0.087 & 0.195 & 0.469 \\ \text { Average } & 0.095 & 0.185 & \\ & & & 0.412\end{array}$

Source: Chambers, Carleton, and McEnally (1988). 



\section{Appendix A}

\section{Derivation of a Closed-Form Solution of $\mathrm{S}_{\mathbf{m}}$}

$S_{m}$ is given in equation (15) of Chapter 2 by:

$$
S_{m}=\sum_{t=1}^{N} \frac{t^{m}}{(1+i)^{t}} .
$$

The expanded form of (A1) can be written:

$$
\mathrm{S}_{\mathrm{m}}=\frac{1^{\mathrm{m}}}{(1+\mathrm{i})^{1}}+\frac{2^{\mathrm{m}}}{(1+\mathrm{i})^{2}}+\ldots+\frac{\mathrm{N}^{\mathrm{m}}}{(1+\mathrm{i})^{\mathrm{N}}} .
$$

Multiplying both sides of $\left(\mathrm{A1}^{\prime}\right)$ by $(1+\mathrm{i})$ and simplifying results in:

$$
\mathrm{S}_{\mathrm{m}}(1+\mathrm{i})=1+\frac{2^{\mathrm{m}}}{(1+\mathrm{i})^{1}}+\ldots+\frac{\mathrm{N}^{\mathrm{m}}}{(1+\mathrm{i})^{\mathrm{N}-1}}
$$

Subtracting (A1') from (A2) gives:

$$
\mathrm{S}_{\mathrm{m}} \mathrm{i}=1-\frac{\mathrm{N}^{\mathrm{m}}}{(1+\mathrm{i})^{\mathrm{N}}}+Z \text {, }
$$

where $\mathrm{Z}$ is given as:

$$
Z=\frac{2^{m}-1^{m}}{(1+i)^{1}}+\frac{3^{m}-2^{m}}{(1+i)^{2}}+\ldots+\frac{N^{m}-(N-1)^{m}}{(1+i)^{N-1}} .
$$

The term $Z$ can also be expressed as:

$$
\mathrm{Z}=\mathrm{T}_{1}+\mathrm{T}_{2}+\ldots+\mathrm{T}_{\mathrm{N}-1},
$$

where $T_{r}$ for any $r=1,2, \ldots, N-1$ is given as follows:

$$
T_{r}=\frac{(1+r)^{m}-r^{m}}{(1+i)^{r}}
$$

Assume the value of $m$ may be either zero or any integer greater than zero. Because the derivations are different, they will be derived separately.

Case 1: $\mathbf{m}=0$

Substituting $\mathrm{m}=0$ in equation (A6): 


$$
T_{r}=\frac{(1+r)^{0}-r^{0}}{(1+i)^{r}}=0
$$

Substituting $T_{r}=0$ in (A5) for all $r=1,2, \ldots, N-1$ defines $Z=0$. Substituting $m=0$ and $Z=0$ in (A3) and simplifying derives the final form for $\mathrm{S} 0$ :

$$
\mathrm{S}_{0}=\frac{1}{\mathrm{i}}\left[1-\frac{1}{(1+\mathrm{i})^{\mathrm{N}}}\right] \text {. }
$$

\section{Case 2: $m \geq 1$}

Expanding equation (A6) and simplifying results in:

$$
T_{r}=\frac{m C_{0}+{ }_{m} C_{1 r}+m_{m} C_{2 r}^{2}+\ldots+m C_{m-1} r^{m-1}}{(1+i)_{r}}
$$

In summation form it is:

$$
T_{r}=\sum_{t=0}^{m-1} \frac{m_{C} t^{t}}{(1+i)^{r}}
$$

Substituting the value of $T_{r}$ from equation (A10) for all values of $r=1,2, \ldots, N-1$ in (A5) gives:

$$
Z=\sum_{r=1}^{N-1} \sum_{t=0}^{m-1} \frac{m^{2} C_{t} r^{t}}{(1+i)^{r}}
$$

Rearranging the summation signs in (A11) results in:

$$
Z=\sum_{t=0}^{m-1} \sum_{r=1}^{N-1} \frac{m C_{t r} r^{t}}{(1+i)^{r}} .
$$

Removing the term $\mathrm{mC}_{\mathrm{t}}$ from the inner summation results in:

$$
Z=\sum_{t=0}^{m-1} m_{t} C_{r=1}^{N-1} \frac{r^{t}}{(1+i)^{r}}
$$

Rearranging and rewriting the terms to change $\sum_{\mathrm{r}=1}^{\mathrm{N}-1}$ to $\sum_{\mathrm{r}=1}^{\mathrm{N}}$ results in:

$$
Z=\sum_{t=0}^{m-1} m C_{t} \sum_{r=1}^{N-1} \frac{r^{t}}{(1+i)^{r}}-\sum_{t=0}^{m-1} m C_{t} \frac{N^{t}}{(1+i)^{N}} .
$$

From equation (A1) it can be seen that:

$$
\sum_{r=1}^{N} \frac{r^{t}}{(1+i)^{r}}=S t \text {. }
$$


Substituting (A15) into (A14) gives:

$$
Z=\sum_{t=0}^{m-1} m_{t} S_{t}-\sum_{t=0}^{m-1} m C_{t} \frac{N^{t}}{(1+i)^{N}}
$$

Substituting the value of $Z$ from (A16) into (A3) results in:

$$
\mathrm{S}_{\mathrm{m}} \mathrm{i}=1-\frac{\mathrm{N}^{\mathrm{m}}}{(1+\mathrm{i})^{N}}+\sum_{\mathrm{t}=0}^{\mathrm{m}-1} \mathrm{mC}_{\mathrm{t}} \mathrm{S}_{t}-\sum_{\mathrm{t}=0}^{\mathrm{m}-1} \mathrm{~m} \mathrm{C}_{t} \frac{\mathrm{N}^{\mathrm{t}}}{(1+\mathrm{i})^{N}} .
$$

Combining terms:

$$
\mathrm{S}_{\mathrm{m}} \mathrm{i}=1+\sum_{\mathrm{t}=0}^{\mathrm{m}-1} \mathrm{mC}_{\mathrm{t}} \mathrm{S}_{\mathrm{t}}-\sum_{\mathrm{t}=0}^{\mathrm{m}} \mathrm{mC}_{\mathrm{t}} \frac{\mathrm{N}^{\mathrm{t}}}{(1+\mathrm{i})^{\mathrm{N}}}
$$

Simplifying further:

$$
S_{m} i=1+\sum_{t=0}^{m-1}{ }_{m} C_{t} S_{t}-\frac{(1+N)^{m}}{(1+i)^{N}}
$$

Dividing both sides by $i$ and simplifying gives us the final form for $S_{m}$ :

$$
\mathrm{S}_{\mathrm{m}}=\frac{1}{\mathrm{i}}\left[1+\sum_{\mathrm{t}=0}^{\mathrm{m}-1} \mathrm{mC}_{\mathrm{t}} \mathrm{S}_{\mathrm{t}}-\frac{(1+N)^{\mathrm{m}}}{(1+\mathrm{i})^{N}}\right] \text { for all } \mathrm{m} \geq 1 \text {. }
$$





\section{Appendix B}

\section{Alternative Derivation of the M-Square Model}

Because the model given in equation (34) of Chapter 4 implies that portfolio M-square should be minimized with a lower bound of zero, an alternative solution is simply to set the portfolio M-square value equal to zero:

$$
\sum_{i=1}^{n} p_{i} \text { M-Square }=0
$$

Substituting the value of M-square $=\mathrm{D}(2)-2 \mathrm{HD}(1)+\mathrm{H}^{2}$ into (A21) and further simplifying gives:

$$
\sum_{i=1}^{n} p_{i} D_{i}(2)=2 H \sum_{i=1}^{n} p_{i} D_{i}(1)-H^{2} \sum_{i=1}^{n} p_{i}
$$

Substituting the value of $\sum_{i=1}^{n} p_{i}=1$ and $\sum_{i=1}^{n} p_{i} D_{i}(1)=H$ from (34) into (A22) gives:

$$
\sum_{i=1}^{n} p_{i} D_{i}(2)=H^{2}
$$

Setting portfolio M-square equal to zero therefore implies the constraint given in (A23). We can now restate the $M$-square model as:

$$
\begin{aligned}
& \text { Objective function: } \operatorname{Min} \sum_{i=1}^{n} p_{i}^{2}, \\
& \text { Subject to: } \sum_{i=1}^{n} p_{i} D_{i}(1)=H, \sum_{i=1}^{n} p_{i} D_{i}(2)=H^{2} \text {, and } \sum_{i=1}^{n} p_{i}=1
\end{aligned}
$$





\section{References}

Babcock, G. C. 1985. "Duration as a Weighted Average of Two Factors." Financial Analysts Joumal (March/April): 75.

Bierwag, G. O., G. G. Kaufman, and C. M. Latta. 1987. "Bond Portfolio Immunization: Tests of Maturity, One- and Two-Factor Duration Matching Strategies." Financial Review (May): 203-19.

1988. "Duration Models: A Taxonomy." Journal of Portfolio Management. (Fall): 50-54.

Bierwag, G. O., G. G. Kaufman, and A. Toevs. 1983. "Bond Portfolio Immunization and Stochastic Process Risk." Journal of Bank Research (Winter): 282-91.

Caks, J., W. R. Lane, R. W. Greenleaf, and R. G. Joules. 1985. “A Simple Formula for Duration.” Jourmal of Financial Research (Fall): 245-49.

Chambers, D. R., W. T. Carleton, and R. M. McEnally. 1988. "Immunizing Default-Free Bond Portfolios with a Duration Vector." Joumal of Financial and Quantitative Analysis (March): 89-104.

Chua, J. 1984. "A Closed-Form Formula for Calculating Bond Duration." Financial Analysts Journal (May/June): 76-78.

1988. “A Generalized Formula for Calculating Bond Duration.” Financial Analysts Journal (September/October):65-67.

Cooper, I. A. 1977. "Asset Values, Interest Rate Changes, and Duration." Journal of Financial and Quantitative Analysis (December): 701-23.

Fisher, L. and R. L. Weil. 1971. "Coping with the Risk of Interest Rate Fluctuations: Returns to Bondholders from Naive and Optimal Strategies.” Joumal of Business (October): 408-31.

Fong, H. G. and O. Vasicek. 1983. "Return Maximization for Immunized Portfolios," in Kaufman, Bierwag, and Toevs, Innovations in Bond Portfolio Management: Duration Analysis and Immunization. Greenwich, CT: JAI Press, Inc.

Hegde, S. P. and K. P. Nunn. 1988. “Non-Infinitesimal Rate Changes and Macaulay Duration.” Joumal of Portfolio Management (Winter): 69-73.

Hicks, J. R. 1939. Value and Capital, Second Edition. Oxford University Press.

Lacey, N. J. and S. K. Nawalkha. 1990. “Convexity: To Minimize or Maximize.” Manuscript, University of Massachusetts.

Macaulay, F. R. 1938. Some Theoretical Problems Suggested by the Movements of Interest Rates, Bond Yields, and Stock Prices in the U.S. Since 1856. New York: National Bureau of Economic Research. 
Maloney, K. J. and D. E. Logue. 1989. “Neglected Complexities in Structured Bond Portfolios.” Joumal of Portfolio Management (Winter): 59-68.

Nawalkha, S. K. and N. J. Lacey. 1988. “Closed-Form Solutions of Higher-Order Duration Measures." Financial Analysts Journal (November/December): 82-84.

Finance (forthcoming).

Nawalkha, S. K., N. J. Lacey, and D. R. Chambers. 1990. "Risks Associated with Bond Convexity." Manuscript, University of Massachusetts.

Nawalkha, S. K., N. J. Lacey, and T. S. Schneeweis. 1990. "Closed-Form Solutions of Convexity and M-Square.” Financial Analysts Joumal (January/February): 75-77.

Redington, F. M. 1952. "Review of the Principles of Life-Office Valuations." Journal of the Institute of Actuaries.

Samuelson, P. A. 1945. "The Effect of Interest Rate Increases on the Banking System." American Economic Review (March):16-27. 